\title{
Plastic Bronchitis Following Fontan Procedure: A Case Report
}

\author{
(1) Eser Doğan, (1) Derya Aydın, (1) Zülal Ülger, (1) Ertürk Levent
}

Ege University Faculty of Medicine, Department of Pediatrics, Division of Pediatric Cardiology, İzmir, Turkey

\begin{abstract}
Fibrinous bronchitis, also known as plastic bronchitis or pseudomembranous bronchitis, usually manifests clinically with non-productive cough and dyspnea. Prior to the expectoration of plaque formations, patients have a history of viral or other respiratory disease. Plastic bronchitis is an extremely rare and fatal complication associated with Fontan procedure. The condition is characterized by the formation of inspissated bronchial casts which may cause life-threatening airway obstructions. Although the pathogenesis of this condition remains unclear, it is believed to involve elevated pulmonary venous pressure, increased central venous pressure, and endobronchial lymphatic leakage. A 9-year-old male patient with Down syndrome underwent Fontan procedure 29 months earlier due to complete endocardial cushion defect and single ventricular physiology. The patient presented to the emergency department due to sudden-onset respiratory distress and fever $\left(38.5^{\circ} \mathrm{C}\right)$. Bilateral diffuse sibilant rhonchi, secretory rales, and intercostal retractions were noted during pulmonary system examination. Posterior-anterior chest $\mathrm{x}$-ray showed cardiomegaly (cardiothoracic ratio $=0.6$ ) and bilateral diffuse infiltration. While under treatment, the patient experienced sudden-onset cough with expectoration of rubbery sputum in the form of branching bronchi-shaped casts. Samples of the inspissated sputum were sent to the Pathology and Microbiology departments for examination. The pathology report indicated fibrinoid material composed of a small number of inflammatory cells and bacterial plaques. Normal bacterial flora was identified in microbiological culture. Clinical presentation can vary from mild clinical findings to life-threatening symptoms. As in our patient, the diagnosis is made clinically, based on expectoration of bronchial casts or their detection during bronchoscopy. As our patient responded well to medical treatment, we proceeded with clinical follow-up. Plastic bronchitis is a very rare entity, and carries a poorer prognosis when it develops after congenital heart disease, as in our case.
\end{abstract}

Keywords: Plastic bronchitis, fontan operation, fibrinous bronchitis

\section{Introduction}

Fibrinous bronchitis, also known as plastic bronchitis or pseudomembranous bronchitis, usually manifests clinically with non-productive cough and dyspnea. Prior to the expectoration of plaque formations, patients have a history of viral or other respiratory disease (1-3). Plastic bronchitis is an extremely rare and fatal complication associated with Fontan procedure. The condition is characterized by the formation of inspissated bronchial casts which may cause life-threatening airway obstruction. Although the pathogenesis of this condition remains unclear, it is believed to involve elevated pulmonary venous pressure, increased central venous pressure, and endobronchial lymphatic leakage (4-6).

\section{Case Report}

A 9-year-old male patient with Down syndrome underwent Fontan procedure 29 months earlier due to complete endocardial cushion defect and single ventricular physiology. The patient presented to the emergency 
department due to sudden-onset respiratory distress and fever $\left(38.5^{\circ} \mathrm{C}\right)$. Bilateral diffuse sibilant rhonchi, secretory rales, and intercostal retractions were noted during pulmonary system examination. Posterior-anterior chest $\mathrm{x}$-ray showed cardiomegaly (cardiothoracic ratio $=0.6$ ) and bilateral diffuse infiltration (Figure 1).

In biochemical analysis, leukocyte count was $5.53 \times 10^{3} /$ $\mu \mathrm{L}$, absolute neutrophil count was $3.4 \times 10^{3} / \mu \mathrm{L}$, and C-reactive protein level was $0.75 \mathrm{mg} / \mathrm{dL}$. Treatment was initiated with ceftriaxone $100 \mathrm{mg} / \mathrm{kg}$ twice daily, salbutamol $0.15 \mathrm{mg} / \mathrm{kg}$ four times daily, and fluticasone $250 \mathrm{mcg}$ twice daily. Transthoracic echocardiography revealed the Fontan procedure, large atrial and ventricular septal defects, no pericardial effusion, maximum $80 \mathrm{mmHg}$ gradient in the area of pulmonary artery banding, and firstdegree atrioventricular valve insufficiency. While under treatment, the patient experienced sudden-onset cough with expectoration of rubbery sputum in the form of branching bronchi-shaped casts (Figure 2).

Samples of the inspissated sputum were sent to the Pathology and Microbiology departments for examination. The pathology report indicated fibrinoid material composed of a small number of inflammatory cells and bacterial plaques. Normal bacterial flora was identified in microbiological culture. In bronchoscopy performed after 7 days of antibiotic therapy, the trachea, main carina, and right and left bronchial systems appeared normal. The absence of any signs of pathology was attributed to the period of antibiotic and inhalation treatment prior to performing the bronchoscopy. The patient's lung auscultation findings resolved during follow-up. Informed consent was obtained. Antibiotic therapy was completed within 14 days and the patient was discharged with instructions to continue nebulizer treatment at home.

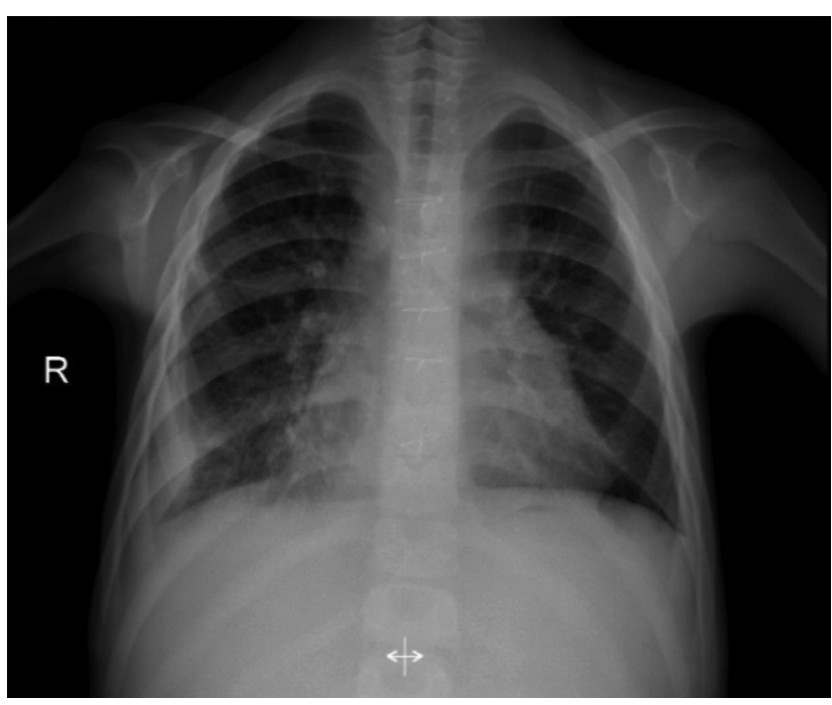

Figure 1. Bilateral diffuse infiltration and increased cardiothoracic ratio on posterior-anterior chest $\mathrm{X}$-ray

\section{Discussion}

Plastic bronchitis was first reported in 131-200 AD by Galen, who described the condition as the expectoration of arteries and veins. Characterized by pathognomonic bronchial casts, the disease was previously described as fibrinous bronchitis and pseudomembranous bronchitis, but has become known as plastic bronchitis in the 20th century (7). Although plastic bronchitis can occur in all age groups, it is more common in childhood, particularly in children over 6 years old. The sex ratio among patients is generally balanced, though some studies have reported female predominance $(7,8)$.

The pathogenesis of plastic bronchitis is not fully understood. Various mechanisms have been proposed, including elevated pulmonary venous pressure, increased inflammatory response, trauma to the bronchial lymphatic system, and ischemia of the bronchial tree (4-6).

Clinical presentation can vary from mild clinical findings to life-threatening symptoms. As in our patient, the diagnosis is made clinically, based on expectoration of bronchial casts or their detection during bronchoscopy. Patients generally present with wheezing, chest pain, fever, and coughing. Atelectasia and infiltration are usually seen in radiological imaging. Computed tomography can be effective in visualizing affected major airways (9).

Seear et al. (10) proposed a classification of two groups based on histological patterns. In Type I, the bronchial casts are composed of fibrin and dense eosinophilic infiltrate

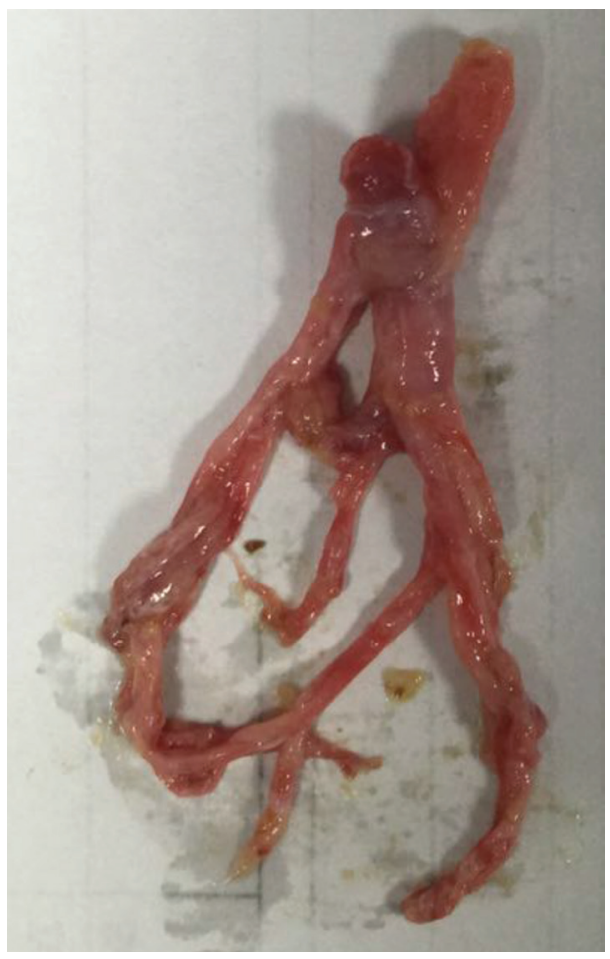

Figure 2. Mucoid bronchial casts expectorated by the patient 
and occur due to acute bronchopulmonary events, while Type II casts contain mucin and are chronic and recurrent in patients who have undergone surgery for congenital cyanotic heart disease. Our patient had Type II casts, which placed him at high risk for mortality.

Treatment strategies vary from medical treatment including steroids and various inhaled lytic agents, to bronchoscopy and other surgical interventions. Although corticosteroids are mostly used in the Type I patient group, they can be used in Type II patients as well. Treatment with various medications such as tissue plasminogen activators, acetylcysteine, macrolide antibiotics, urokinase, and DNase has been attempted via nebulized delivery. Bronchoscopy is routinely practiced in both groups and can be used repeatedly to clear the large airways (11-15).

Some authors have reported performing thoracic duct ligation as treatment. In one such report, high intrathoracic lymphatic pressure was believed to be the cause of recurrent, medically refractory cast formation in two patients who developed plastic bronchitis after undergoing Fontan operations. The patients were reported to be asymptomatic for two years following thoracic duct ligation. The authors stated that thoracic duct ligation cured patients by decreasing intrathoracic lymphatic flow and pressure. However, these two patients were classified as Type II, and it has been suggested that this approach cannot be used for Type I plastic bronchitis $(16,17)$. As our patient responded well to medical treatment, we proceeded with clinical follow-up.

Plastic bronchitis is a very rare entity, and carries a poorer prognosis when it develops after congenital heart disease, as in our case.

\section{Ethics}

Informed Consent: Informed consent was obtained.

Peer-review: Externally peer-reviewed.

\section{Authorship Contributions}

Surgical and Medical Practices: E.D., Z.Ü., Concept: E.D., E.L., Design: E.D., Data Collection or Processing: Z.Ü., Analysis or Interpretation: E.D., E.L., Literature Search: D.A., E.L., Writing: E.D., D.A.

Conflict of Interest: No conflict of interest was declared by the authors.

Financial Disclosure: There are no financial conflicts of interest to disclose.

\section{References}

1. Park JY, Elshami AA, Kang DS, Jung TH. Plastic bronchitis. Eur Respir / 1996;9:612-4.

2. Shikanai K. Two cases of fibrinous bronchi-tis. Jap / Med 1966;5:1-7.

3. Saracoğlu K. A Case of fibrinous bronchitis. Br Med J 1960;1:1548.

4. Cajaiba MM, BorralhoP, Reyes-Mugica M. The potentially lethal nature of bronchial casts: plastic bronchitis. Int I Surg Pathol 2008;16:230-2.

5. Bowen A, Oudjhane K, Odagiri K, Liston SL, Cumming WA, Oh KS. Plastic bronchitis: large, branching, mucoid bronchial casts in children, AJR Am J Roentgenol 1985;144:371-5.

6. Moser C, Nussbaum E, Cooper DM. Plastic bronchitis and the role of bronchoscopy in the acute chest syndrome of sickle cell disease. Chest 2001;120:608-13.

7. Eberlein $\mathrm{MH}$, Drummond MB, Haponik EF. Plastic bronchitis: a management challenge. Am J Med Sci 2008;335:163-9.

8. Brogan TV, Finn LS, Pyskaty DJ Jr, et al. Plastic bronchitis in children: a case series and review of the medical literature, Pediatr Pulmonol 2002;34:482-7.

9. Barber BJ, Burch GH, Tripple D, Balaji S. Resolution of plastic bronchitis with atrial pacing in a patient with fontan physiology, Pediatr Cardiol 2004;25:73-6.

10. Seear M, Hui H, Magee F, Bohn D, Cutz E. Bronchial casts in children: a proposed classification based on nine cases and a review of the literature. Am J Respir Crit Care Med 1997;155:36470.

11. Costello JM, Steinhorn D, McColley S, Gerber ME, Kumar SP. Treatment of plastic bronchitis in a Fontan patient with tissue plasminogen activator: a case report and review of the literature. Pediatrics 2002;109:e67.

12. Wakeham MK, Van Bergen AH, Torero LE, Akhter J. Longterm treatment of plastic bronchitis with aerosolized tissue plasminogen activator in a Fontan patient. Pediatr Crit Care Med 2005;6:76-8.

13. Quasney MW, Orman K, Thompson l, et al. Plastic bronchitis occurring late after the Fontan procedure: treatment with aerosolized urokinase. Crit Care Med 2000;28:2107-11.

14. Stiller B, Riedel F, Paul K, van Landeghem FK. Plastic bronchitis in children with Fontan palliation: analogue to protein losing enteropathy? Pediatr Cardiol 2002;23:90-4.

15. Shinkai M, Rubin BK. Macrolides and airway inflammation in children. Paediatr Respir Rev 2005;6:227-35.

16. Shah SS, Drinkwater DC, Christian KG. Plastic bronchitis: is thoracic duct ligation a real surgical option? Ann Thorac Surg 2006;81:2281-3.

17. Nayar S, Parmar R, Kulkarni S, Cherian KM. Treatment of plastic bronchitis. Ann Thorac Surg 2007;83:1884-6. 